\title{
Contamination of Japanese foodstuffs of terrestrial origin after the Fukushima nuclear accident and related dose assessment
}

\section{Part 2: ingestion dose assessments for the first year after the accident}

Ph. Renaud ${ }^{\text {a }}$, M. Simon-Cornu, M.-A. Gonze, C. Mourlon, V. Parache, I. Korsakissok, E. Navarro, B. Cessac, A. Rannou and D. Champion

IRSN, Pôle de Radioprotection, BP3, 13108 Saint-Paul-Lez-Durance, France.

Received 5 April 2013 - Accepted 27 June 2013

\begin{abstract}
This article proposes an assessment of the ingestion doses potentially received by people living in the Japanese areas most severely affected by the radioactive deposits due to the Fukushima nuclear accident. The assessment distinguishes two consecutive periods: the first 2 months (March 15th to May 15th 2011) and the rest of the year 2011, according to the two main foodstuff contamination periods identified (Renaud et al., 2013). On the basis of the worstcase hypothesis that can reasonably be made, the estimated doses are much lower than they might have been in other circumstances, on account of generally moderate levels of contamination for most foods, early evacuation of the most severely affected areas and the consumption bans ordered by the Japanese authorities. Thus, a single ingestion of $100 \mathrm{~g}$ of leafy vegetables in the early days by a one-year-old child living in non-evacuated localities near Iitate and Kawamata could have led to an equivalent dose to the thyroid of about $25 \mathrm{mSv}$; and to a thyroid dose of about $140 \mathrm{mSv}$ for the rather unrealistic scenario of a daily consumption. Because of the rapid decrease in the contamination of vegetables and a much weaker contamination of other crops, and thanks to measures taken by the authorities (prohibition of consumption, use of certain fodder, etc.), the ingestion doses potentially received during the remainder of the year 2011 are estimated to be below $1 \mathrm{mSv}$. In the event that sales limits would have been ignored, only repeated consumption of mushrooms would have led to doses above that level. Even with the worst-case hypotheses, the doses potentially caused by ingestion are much lower than those resulting from outdoor exposure to radioactive deposits: approximately several millisieverts in a year for the population living in the non-evacuated localities near Iitate and Kawamata.
\end{abstract}

Keywords: Fukushima NPP accident / foodstuff contamination / ingestion / dose assessment

\section{Introduction}

The date of the Fukushima accident, which occurred very early in the growing and breeding seasons, limited fallout contamination of most foodstuffs of terrestrial origin. The highest activity - several tens of thousands of $\mathrm{Bq} / \mathrm{kg}$ of ${ }^{131} \mathrm{I}$, ${ }^{134} \mathrm{C}$ and ${ }^{137} \mathrm{C}$ - showed up only in leafy vegetables (Renaud et al., 2013). In the case of orchards, the low interception of the deposits due to the lack of leaves for most trees led to a moderate contamination of fruits. Moreover, by mid-March 2011, the annual crops such as grains were very far from the flowering stage, which determines how intensely radionuclides are transferred from the leaves to edible organs, and rice had not yet been planted. Thus, the date of the accident explains why agricultural foodstuff contamination has rarely exceeded $1000 \mathrm{~Bq} / \mathrm{kg}$ except for leafy vegetables.

\footnotetext{
a philippe.renaud@irsn.fr
}

In the case of meat and dairy products, the common Japanese practice of feeding animals with imported fodder increased the effect of the accident's date. Farmers already had stocks of feed from established supply channels, so they did not use local feed. Thus, the highest activities measured in milk were of the order of 10 to $100 \mathrm{~Bq} / \mathrm{L}$, with a maximum of $210 \mathrm{~Bq} / \mathrm{L}$ for ${ }^{137} \mathrm{Cs}$, and of the order of 100 to $1000 \mathrm{~Bq} / \mathrm{L}$ for ${ }^{131} \mathrm{I}$, with a maximum of $5300 \mathrm{~Bq} / \mathrm{L}$.

Based on these findings, a dose assessment due to the ingestion of contaminated foodstuffs is proposed considering two periods: March 15th to May 15th 2011, i.e. the acute foodstuff contamination phase, and May to December 2011. This assessment provides upper estimates of ingestion doses possibly received by people living in the most severely affected unevacuated towns, assuming that they are totally self-sufficient for food and that they observed the consumption bans ordered by the Japanese authorities. Doses resulting from a consumption of $1 \mathrm{~kg}$ of foodstuffs having reached the highest activity level measured are also provided for information. 
Table 1. Standards for sale or consumption established in Japan following the Fukushima accident, effective from March 29th 2011 to March 31th 2012.

\begin{tabular}{|c|c|c|c|c|c|}
\hline $\mathrm{Bq} / \mathrm{kg}$ & $\begin{array}{c}\text { Foodstuffs } \\
\text { for newborns }\end{array}$ & $\begin{array}{c}\text { Milk and } \\
\text { dairy products }\end{array}$ & Vegetables & Cereals & $\begin{array}{c}\text { Meat, fish } \\
\text { and eggs }\end{array}$ \\
\hline iodines & 100 & 300 & 2000 & - & - \\
\hline caesiums & 200 & 200 & 500 & 500 & 500 \\
\hline
\end{tabular}

\section{Brief history of actions taken by the Japanese authorities to protect the population}

The accident at Fukushima led the Japanese authorities to initiate actions to protect the population, firstly against the immediate impact of the releases (exposure to the radioactive plume) and then against the radioactive deposits formed by the atmospheric dispersion of these releases (external exposure to radiation emitted by the deposits and internal contamination by ingestion of contaminated foodstuffs). In addition to radioactivity measurements aiming to characterise deposits, a monitoring of foodstuff contamination and practical rules of foodstuff management were established. The information sources available to the IRSN, most notably the report concerning the Fukushima accident sent by the Japanese government to the IAEA on June 7th 2011 (Japanese Government, 2011), provide a chronology of the main population protection decisions taken from the start of the accident.

On March 11th 2011, at 8:50 pm, less than 6 hours after the tsunami, the Governor of Fukushima District ordered the evacuation of the towns of Futuba and Okuma, located within a $2-\mathrm{km}$ radius, then extended to a $3-\mathrm{km}$ and $10-\mathrm{km}$ radius. On March 12th at 6:25 pm, following the explosion in Reactor Building 1, the evacuation zone around the Fukushima Dai-ichi site was extended to $20 \mathrm{~km}$, and a shelter zone in a radius from 20 to $30 \mathrm{~km}$ around the site was set up on March 15 th at $11 \mathrm{am}$. On March 15th, the NISA announced that the evacuation of inhabitants in a $20-\mathrm{km}$ radius around Fukushima Dai-ichi had been effective since that day at $7 \mathrm{pm}$.

At the end of March, while the major atmospheric releases had dissipated, the results of the initial measurement campaigns revealed significant dose rates beyond the $20-\mathrm{km}$ evacuation zone due to deposits, and particularly toward the north-west. Moreover, certain inhabitants located between 20 and $30 \mathrm{~km}$ started to evacuate that area voluntarily because their economic and social life was becoming increasingly difficult to sustain. In this context, local initiatives and new decisions by the government authorities were implemented to supplement the emergency protective actions taken in March. Iitate, Namie, and part of the Kawamata and Minamisoma populations were asked to leave within one month (first announcement). On May 15th, 4000 residents of Iitate and 1300 of Kawamata (municipalities located in the extended evacuation zone decided in April) were re-housed in neighbouring towns. Later, evacuation of people residing in "hot spots" (with a dose rate greater than $20 \mathrm{mSv} /$ year) was decided.

With regard to the mechanism for monitoring foodstuffs, Japan relies on the standards for sale or consumption defined by the Japanese Ministry of Health, Labour and Welfare
(MHLW) on March 17th 2011 and validated by the FSC (Japanese food safety commission) on March 29th (Tab. 1). Exceeding these standards leads to the implementation of bans.

This mechanism is not comparable to a zoning system. In Japan, it is not implemented via the definition of a perimeter in which actions are applied. The controls and bans are applied on a case-by-case basis according to the specific strategy implemented by each local government concerned by the consequences of the accident.

The Japanese Ministry of Education, Culture, Sport, Science and Technology (MEXT), however, issued certain general rules. The system of bans and lifting of restrictions thus operated in the following way during the past year:

- marketing authorisation is granted $a$ priori; restrictions are not implemented unless a posteriori tests reveal values exceeding the standards,

- testing is performed by sampling, but the exact protocol is never disclosed; some doubt therefore remains concerning the representativeness of the samples on the scale of the farms, municipalities, or districts concerned,

- the procedure for lifting bans appears to be strict: selection of several sampling points, performance of weekly tests on foodstuffs at those points, and the possibility of lifting the ban only if measurement results for three consecutive weeks are within the limits.

This management mechanism was applied to many categories of products in Japan, but the dates, duration and areas in which it was applied were variable.

The information currently available does not enable the IRSN to fully evaluate the effectiveness of the food contamination management mechanism in Japan. In particular, it seems that the restrictions are sometimes implemented rather late and non-exhaustively, which has led the Japanese population to partly lose confidence in this mechanism. A few observations may cast doubt on the effectiveness of the system implemented:

- certain restrictions were implemented very late, after measurement results exceeding the limits had been obtained; for bamboo shoots, for example, the results from samples taken on April 27th 2011 in Iwaki (Fukushima district) exceeded the limits, but the restriction on sale did not take effect until May 9th 2012;

- certain types of produce underwent sampling with results exceeding the limits without giving rise to restrictions on a national level, and products with contamination exceeding the limits were detected on the Japanese market (tea leaves, algae and mussels, loquat);

- certain municipalities were subject to restrictions although no samples were taken there or the samples all produced results within the limits; 


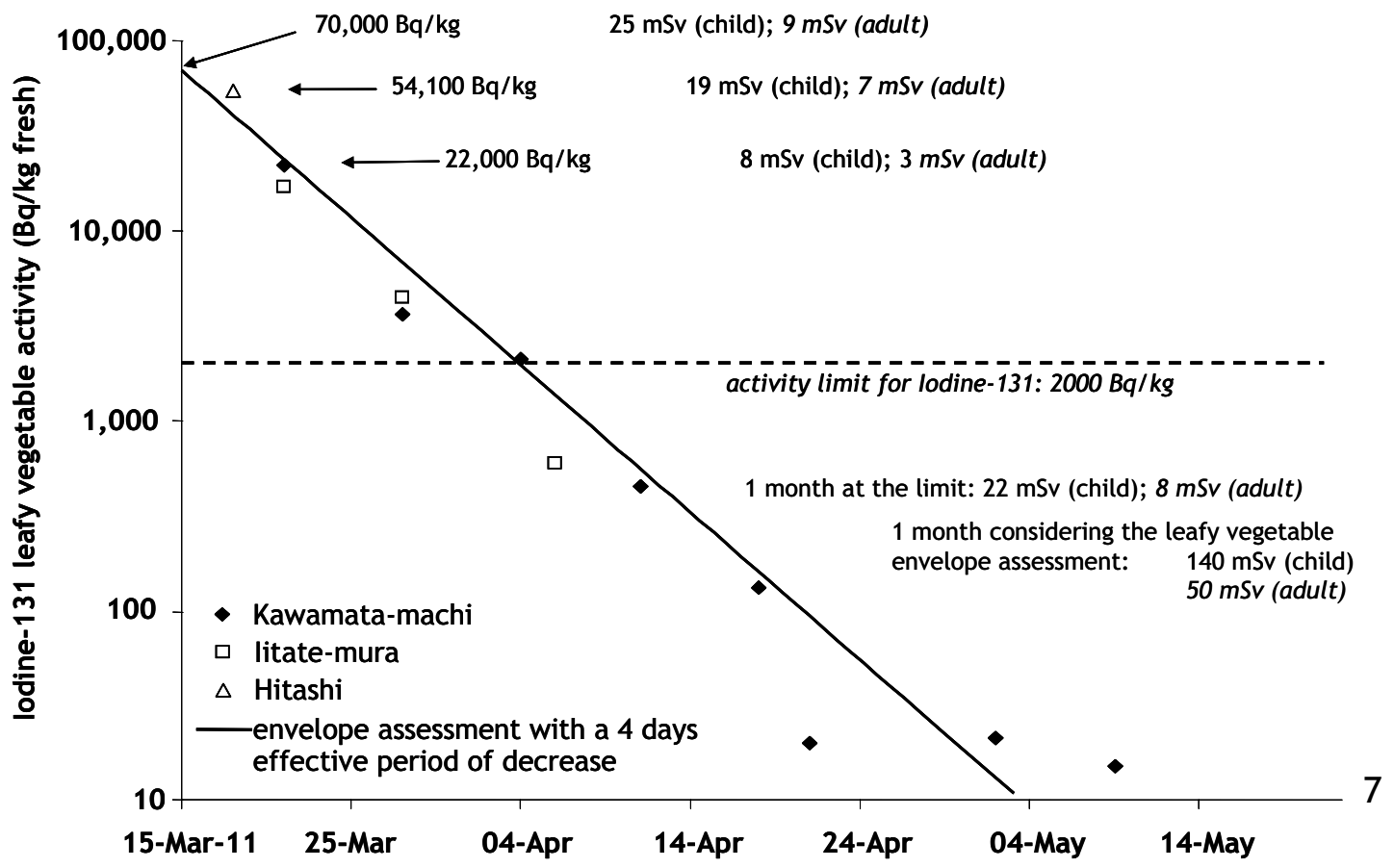

Fig. 1. ${ }^{131} \mathrm{I}$ activity evolution $(\mathrm{Bq} / \mathrm{kg})$ in leafy vegetables sampled in Kawamata-Machi and Iitate-Mura, maximum activity measured in leafy vegetables (from Hitashi) and corresponding thyroid doses in $\mathrm{mSv}$ for a one-year-old child and for an adult. Ingestion rates are $100 \mathrm{~g}$ (or $100 \mathrm{~g} / \mathrm{d}$ ) for the child and $300 \mathrm{~g}(300 \mathrm{~g} / \mathrm{d})$ for the adult.

- marketing restriction is not always associated with consumption restriction;

- there is no systematic application of the three tests before release, or the information concerning the representativeness of the tests performed is very patchy.

\section{Ingestion dose estimates related to the first month after the radioactive deposits formed}

Evacuation from an area within a $20-\mathrm{km}$ radius of the power plant before the main radioactive deposits formed made it impossible to consume any local foodstuffs there. Subsequent evacuation of the most severely affected localities until as late as 15 May (Iitate-Mura, Kawamata-Machi, Minamisoma-Shi, etc.), the announcement of the accident and the ensuing alarm, exacerbated by consumption prohibitions, mean that local products were probably not consumed on a regular basis (Taira et al., 2012). However, dose reconstructions for people who were in these areas, based on urine samples, show that local foodstuffs were occasionally consumed during this period (Kamada et al., 2012).

During this period, the equivalent dose to the thyroid linked to ${ }^{131} \mathrm{I}$ incorporation is the most representative indicator of the ingestion exposure.

Due to the date of the winter Fukushima accident, very early in the agricultural and livestock calendars, the highest contamination levels during the first two months concerned only leafy vegetables. The highest activity from all kinds of foodstuffs that the MHLW measured and published was found to be $54100 \mathrm{~Bq} / \mathrm{kg}$ of ${ }^{131} \mathrm{I}$ in a spinach sample taken on March 18th in Hitashi, 120 kilometres south of the plant. The maximum activities of ${ }^{131}$ I measured in other vegetables and milk were more than 10 times lower than those measured in leafy vegetables, and most importantly, these values were much more rarely observed.

So, the consumption of leafy vegetables, even very occasionally, was potentially the predominant route of exposure by ingestion during this period.

Figure 1 presents the evolution of ${ }^{131}$ I activity measured in vegetables sampled in Kawamata-Machi and Iitate-Mura during the first month after deposits. This figure also provides the thyroid equivalent doses corresponding to a single consumption of $100 \mathrm{~g}$ of leafy vegetables by a one-year-old child and to a single consumption of $300 \mathrm{~g}$ by an adult (in italics), for three activity values:

- the highest iodine activity from all kinds of foodstuffs measured and published by the MHLW: $54100 \mathrm{~Bq} / \mathrm{kg}$ in spinach sampled on March 18th in Hitashi,

- the highest ${ }^{131} \mathrm{I}$ activity measured in spinach from Kawamata-Machi and sampled on the 22 March: $22000 \mathrm{~Bq} / \mathrm{kg}$ fresh,

- the highest theoretical activity potentially reached in Kawamata-Machi, estimated according to the evolution observed after March 15th, i.e. 70000 Bq/kg.

The equivalent doses to the thyroid estimated for a child (from 8 to $25 \mathrm{mSv}$ ) are always higher than those to an adult ( 3 to $9 \mathrm{mSv}$ ), despite the difference in the ingestion rate, due to the fact that the dose conversion factor for a one-year-old child is more than 8 times higher than that for an adult. In both 
cases the calculated dose decreases with the massic activity of vegetables.

This evaluation supposes that the population generally respected the consumption bans decided by the Japanese government but could have accidentally consumed a product exceeding the activity limit.

Figure 1 also provides the dose corresponding to a daily consumption of leafy vegetables $(100 \mathrm{~g} / \mathrm{d}$ for a one-year-old child and $300 \mathrm{~g} / \mathrm{d}$ for an adult), contaminated by iodine at the activity limit fixed by the Japanese government $(2000 \mathrm{~Bq} / \mathrm{kg})$ : $22 \mathrm{mSv}$ for a child and $8 \mathrm{mSv}$ for an adult. These doses are to be compared with those reconstructed by Kamada et al. (2012): from 27 to $66 \mathrm{mSv}$ for 4 adults and one 14-year-old child living in Iitate-Mura and Kawamata-Machi. The urine was sampled on May 5th (54 days after deposition). Among the 5 people who presented an ${ }^{131}$ I activity of their urine from 0.69 to $1.8 \mathrm{~Bq} / \mathrm{L}, 4$ declared in their interview that they ate vegetables from their gardens around the end of April (about 45 days after deposits and about one week before the urine sampling). Considering that the kind of food consumed by these people was not necessarily as contaminated as the samples considered previously, it appears that some people may have consumed more than one kilogramme of such contaminated foods, widely exceeding the activity limit. Therefore, the case of a regular consumption of leafy vegetables produced in Kawamata-Machi, which would have initially appeared as a rather unrealistic scenario, can be envisaged. Considering a decrease in the activity of leafy vegetables, with a period of 4 days allowing fitting the measured activities (Renaud et al., 2013), and using the previous consumption rate, the corresponding "envelope" thyroid doses can be estimated in the order of $140 \mathrm{mSv}$ for a child and $50 \mathrm{mSv}$ for an adult.

Otherwise, nothing allows one to affirm that the samples of leafy vegetables measured in Kawamata and Iitate are representative of the highest contamination levels reached in these areas. Using the Symbiose software (Gonze et al., 2012) and on the basis of the first campaign of soil sampling coordinated by the MEXT, Renaud et al. (2013) have assessed some ${ }^{131}$ I activity levels in leafy vegetables in the order of 10 times higher than those measured. Various elements lead us to think that these are overestimated results. However, a regular consumption of such contaminated foodstuffs could have led to thyroid doses ten times higher than the above-mentioned estimates.

\section{Ingestion dose estimates for the period from May to the end of 2011}

Koizumi et al. (2011) performed evaluations of doses by ingestion based on measurements made during a week in July 2011 in whole-day meal sets purchased in shops in four towns: Fukushima, Iwaki, Soma and Nihonmatsu. The doses evaluated were extrapolated by Koizumi et al. over the course of a year; they range from "non-calculable" (activity below detection limits) to $80 \mu \mathrm{Sv} / \mathrm{an}$ (in Soma). Several possible explanations can account for such low levels. In addition to the contextual factors described above, bans on consuming certain foodstuffs probably raised awareness of the potential contamination of all local foodstuffs. Moreover, as mentioned by the authors, the calculated doses are not representative of the levels that people consuming locally produced foodstuffs on a regular basis may have received.

Without specific information, it is always difficult to estimate the proportion of locally produced foodstuffs in a diet, even more so in the special context of a post-accident situation. However, in order to provide an upper limit of effective doses by ingestion for the period from May to December 2011, Table 1 presents the case of a person who would have lived in one of the three towns with the highest food contamination (Kawamata-Machi, Iitate-Mura and Minamisoma-Shi) and would have consumed only foodstuffs with the actually measured contamination levels. The available measurements from the MHLW website (www.mhlw.go.jp/english) make it possible to calculate the average activity for all the main categories of foodstuffs of terrestrial origin produced in these towns: grains (especially rice and wheat), legumes (especially soya beans), potatoes, vegetables, seeds, nuts, fruits, mushrooms, meat and eggs. After May, bans on the consumption of the products affected (mainly beef, bamboo shoots, Japanese apricots, yusus and kiwis) were probably known and were probably observed. That is why findings that exceeded standards were not taken into account in calculations of average activity.

The data used for the assessment are presented in Table 2. No food was found to be more contaminated than another during this period, in contrast with the case of leafy vegetables in the first two months: average activity ranged from 15 to $103 \mathrm{~Bq} / \mathrm{kg}$. The initials ND (non-determined) for milk and dairy products refer to the absence of caesium activity above the detection limits during this period. These categories of foodstuffs are those included in a study of the national diet in Japan from 1975 to 2008, provided by the Japanese Ministry of Health (MHLW, 2012) and the associated intake rates are consistent with those used by the World Health Organization for people over the age of 20 in its preliminary dose estimation (WHO, 2012). Table 2 also shows the 2008 food intake rate and average activity chosen to calculate doses.

These hypotheses lead to an effective dose by ingestion from May to December 2011 on the order of $0.6 \mathrm{mSv}$ for an adult, as a result of very moderate contamination levels observed in agricultural foods.

Doses due to a consumption of $1 \mathrm{~kg}$ of different types of food at the maximal activities measured (including when they exceeded the consumption limit) are presented in Table 3. These data show that a single consumption of $1 \mathrm{~kg}$ of mushrooms would have led to a dose of the same order as those of the previous assessment. Only repeated consumption of mushrooms at the highest contamination levels measured, and totally ignoring the consumption limits, would have allowed reaching the annual effective dose of $1 \mathrm{mSv} /$ year.

\section{Conclusion}

Regarding the doses resulting from ingestion of food produced in the most affected and non-evacuated areas, this article provides estimates based on available measurements and considering both realistic and penalising assumptions of consumption. This assessment aims to provide orders of magnitude and 
Table 2. Effective doses potentially received by an adult consuming regularly foods of terrestrial origin produced in the towns of litate, Kawamata or Minamisoma from May to December 2011. The daily food intake rate used in the calculation and the average activity measured in the towns during the period considered are shown for each food category.

\begin{tabular}{|c|c|c|c|c|}
\hline Food category & $\begin{array}{c}\text { Food } \\
\text { intake rate } \\
(\mathrm{g} / \mathrm{d})\end{array}$ & $\begin{array}{c}{ }^{134} \mathrm{Cs} \\
\text { mean activity } \\
(\mathrm{Bq} / \mathrm{kg})\end{array}$ & $\begin{array}{c}{ }^{137} \mathrm{Cs} \\
\text { mean activity } \\
(\mathrm{Bq} / \mathrm{kg})\end{array}$ & $\begin{array}{l}\text { Ingestion effective } \\
\text { dose due to mean } \\
\text { activity }(\mu \mathrm{Sv})\end{array}$ \\
\hline Grain (wheat, rice, etc.) & 449 & 103 & 83 & 332 \\
\hline Potatoes & 57 & 15 & 17 & 7 \\
\hline Legumes (soya beans, etc.) & 56 & 38 & 45 & 18 \\
\hline Seeds and nuts & 2 & 74 & 97 & 1 \\
\hline Vegetables (green, yellow, other) & 260 & 70 & 67 & 155 \\
\hline Fruits & 117 & 53 & 54 & 52 \\
\hline Mushrooms & 15 & 71 & 73 & 9 \\
\hline Meat and eggs & 111 & 20 & 20 & 17 \\
\hline Milk and dairy products & 111 & ND & ND & \\
\hline $\begin{array}{c}\text { Sum of these } \\
\text { ingestion effective } \\
\text { doses }(\mu \mathrm{Sv})\end{array}$ & & & & 567 \\
\hline
\end{tabular}

Table 3. Effective doses potentially received by an adult who would have consumed $1 \mathrm{~kg}$ of foodstuffs of terrestrial origin produced in Iitate, Kawamata or Minamisoma, taking into account the highest activity measured in these towns from May to December 2011.

\begin{tabular}{|c|c|c|c|}
\hline Food category & $\begin{array}{c}{ }^{134} \text { Cs maximum } \\
\text { activity } \\
(\mathrm{Bq} / \mathrm{kg})\end{array}$ & $\begin{array}{l}{ }^{137} \text { Cs maximum } \\
\text { activity } \\
(\mathrm{Bq} / \mathrm{kg}) \\
\end{array}$ & $\begin{array}{l}\text { Effective dose due to ingestion } \\
\text { of } 1 \mathrm{~kg} \text { of food with maximum } \\
\text { activity contamination }(\mu \mathrm{Sv})\end{array}$ \\
\hline Grain (wheat, rice, etc.) & 220 & 260 & 8 \\
\hline Potatoes & 39 & 59 & 2 \\
\hline Legumes (soya beans, etc.) & 79 & 100 & 3 \\
\hline Seeds and nuts & 130 & 170 & 5 \\
\hline Vegetables (green, yellow, other) & 1,500 & 1,600 & 49 \\
\hline Fruits & 1,100 & 1,300 & 38 \\
\hline Mushrooms & 8,900 & 11,000 & 312 \\
\hline Meat and eggs & 2,175 & 2,175 & 70 \\
\hline Milk and dairy products & ND & ND & \\
\hline
\end{tabular}

to put into perspective the problems posed by the consumption of terrestrial food compared with other routes of exposure.

On the basis of the worst-case hypothesis that can reasonably be made, the estimated doses due to the ingestion of contaminated foods were much lower than they could have been in other circumstances, on account of generally moderate contamination levels for most food categories, early evacuation of the most severely affected areas and the consumption bans ordered by the Japanese authorities.

As expected, it is during the first month following the radioactive deposits that doses due to ingestion of contaminated foods could have been the highest. Thus, a single ingestion of $100 \mathrm{~g}$ of leafy vegetables in the early days by a one-year-old child living in non-evacuated localities near Iitate and Kawamata could have led to an equivalent dose to the thyroid of about $25 \mathrm{mSv}$; and to a thyroid dose of about $140 \mathrm{mSv}$ for the rather unrealistic scenario of a daily consumption. This shows the merits of quickly controlling and prohibiting food of local origin in the contaminated territories, as recommended by the French Steering Committee for the Management of the PostAccident Phase of a Nuclear Accident (ASN, 2010).

Because of the rapid decrease in the contamination of vegetables and a much weaker contamination of other crops, and thanks to protection measures taken by the Japanese authorities (prohibition of consumption, use of certain fodder, etc.), the ingestion doses potentially received during the rest of the year 2011 were estimated to be below $1 \mathrm{mSv}$. In the event that food restriction limits were ignored, only repeated consumption of mushrooms could have led to doses above that level. Despite the worst-case hypotheses, the doses potentially caused by ingestion were found to be much lower than those resulting from outdoor exposure to radioactive deposits: approximately several millisieverts in a year for people in the non-evacuated localities near Iitate and Kawamata.

The monitoring of the radioactivity of foodstuffs will probably show that the doses received by consumers of local foodstuffs are likely to further decrease in the coming years.

\section{References}

ASN (2010) CODIR-PA: Steering Committee for the Management of the Post-Accident Phase of a Nuclear Accident or a Radiological Situation; report of working group no. 2: food, agriculture and life in contaminated rural areas, Autorité de Sûreté Nucléaire, 26 April 2010.

Gonze M.A., Simon-Cornu C., Métivier J.M., Garcia-Sanchez L., Mourlon C., Parache V. (2012) Landscape-level Model Predictions of ${ }^{131} \mathrm{I},{ }^{134} \mathrm{Cs}$ and ${ }^{137} \mathrm{Cs}$ transfer through terrestrial systems in the $80-\mathrm{km}$ Fukushima-Daiichi area using the Symbiose Platform, IRPA, May 2012, Glasgow. 
Japanese Government (2011) Report of the Japanese Government to the IAEA Ministerial Conference on Nuclear Safety - The Accident at TEPCO's Fukushima Nuclear Power Stations.

Kamada N., Saito O., Endo S., Kimura A., Shizuma K. (2012) Radiation doses among residents living $37 \mathrm{~km}$ northwest of the Fukushima Dai-ichi Nuclear Power Plant, J. Environ. Radioact. 110, 84-89.

Koizumi A., Harada K., Niisoe T., Adachi A., Fujii Y., Hitomi T., Kobayashi H., Wada Y., Watanabe T., Ishikawa H. (2011) Preliminary assessment of ecological exposure of adult residents in Fukushima Prefecture to radioactive cesium through ingestion and inhalation, Environ. Health Prev. Med., DOI 10.1007/s12199-011-0251-9.

MHLW (2012) Trends in Food Intake by Food Group, 1975 to 2008 (Per capita per day, National Average), extrait du document http:// www.mhlw.go.jp/bunya/kenkou/eiyou/dl/h20-houkoku-06.pdf, page consultée le 10/11/2012.
Renaud Ph., Simon-Cornu M., Gonze M.-A., Mourlon M., Parache V., Korsakissok I., Navarro E., Cessac B., Rannou A., Champion D. (2013) Contamination of Japanese foodstuffs of terrestrial origin after the Fukushima nuclear accident and related dose assessments; Part 1: foodstuffs contamination, DOI: 10.1051/radiopro/2013081.

Taira Y., Hayashida N., Yamashia S., Kudo T., Matsuda N. Takahakada J., Gutevitc A., Kazlovsky A., Takamura N. (2012) Environmental contamination and external radiation dose rates from radionuclides released from the Fukushima nuclear power plant, Radiat. Prot. Dosim. 151 (3), 537-545.

WHO (2012) Preliminary dose estimation from the nuclear accident after the 2011 Great East Japan earthquake and tsunami ISBN 978-92-4-150366-2.

Cite this article as: Ph. Renaud, M. Simon-Cornu, M.-A. Gonze, C. Mourlon, V. Parache, I. Korsakissok, E. Navarro, B. Cessac, A. Rannou, D. Champion. Contamination of Japanese foodstuffs of terrestrial origin after the Fukushima nuclear accident and related dose assessment, Radioprotection 49(1), 17-22 (2014). 